\title{
VITAMIN D.
}

\author{
By LEONARD FINDLAY, M.D., F.R.C.P. \\ (Physician, Princess Elizabeth of York Hospital for Children, London.)
}

Avitaminosis so far as Vitamin D is concerned spells rickets.

It was Hopkins of Cambridge who in 1906 first suggested that rickets might be caused by the absence of some essential and vital element in the diet, an accessory food factor as he called it at the time. Hopkins suspected something associated with animal fat, perhaps the fat-soluble A factor and now called vitamin A, with which he had already carried out extensive animal experiments. Hopkins had made the observation, an observation which has stood the test of time, that this element (fat-soluble A or vitamin A as it is now called) influences growth and in consequence it was often spoken of as the growth-promoting factor.

Some few years after this date, his disciple Mellanby commenced a series of experiments in the dog on carefully controlled diets and he reported in I9I9 that by withholding animal fat (the vehicle of the fat-soluble A factor) he had been successful in producing rickets in his experimental animals.

The next important chapter in the history of the search for the cause of rickets was the introduction of the rat instead of the dog as the experimental animal by McCollum of Baltimore in 1922. This innovation had the great advantage that experiments could be carried out on a much more extensive scale and free of the many drawbacks which were associated with those in the dog. In the first place, rats were cheaper than dogs and, owing to their greàt fertility, it was possible to obtain large numbers of an experimental animal of the one stock and so eliminate the question of varying susceptibility. Moreover, their rate of growth was quicker so that rickets developed in about one third of the time necessary in the case of the dog.

McCollum and his co-workers in their experiments with the rat controlled the diet in all its various constituents, mineral as well as organic, to a degree that had not been done previously. After numerous trials with varying diet mixtures these workers found that, if the diet fed the experimental animals was deficient in phosphorus, but contained ample calcium, a condition of the bones indistinguishable histologically from human rickets was induced. They also found that if control animals fed on this diet were given at the same time cod-liver oil, which is rich in the fat-soluble A factor , or vitamin $\mathrm{A}$, the disease would not develop.

These findings at first sight seemed to confirm Mellanby's results, but since it was demonstrated that all substances containing vitamin A, e.g. different examples of animal fat, were not efficacious in preventing the development of the rachitic changes in the bones, it seemed possible that cod-liver oil owed its virtue as a preventative of rickets to the fact that it contained in addition to vitamin A something else which was perhaps the real factor in preventing the onset of the disease. This is indeed what McCollum found to be the case because, when he submitted cod-liver oil to the process of oxidation, which he did by the application of heat while the oil was agitated, he discovered that the oil had lost all power of stimulating growth but that it remained potent against the development of rickets. From these experiments it was postulated that there existed another factor distinct from fat-soluble A (vitamin A) which was responsible for the prevention of rickets and which at the time was provisionally named the anti-rachitic or $\mathrm{X}$ factor. It is this substance which is now called vitamin $\mathrm{D}$. 
Although these experiments showed how rickets could be prevented, induced and cured in the rat, it was nevertheless difficult to see how they could explain the incidence of the disease as it occurred in man. Perhaps the chief objection to the application of the experimental findings to human pathology was the fact that an antirachitic power was only possessed to any appreciable degree by one article of food, viz. :- the yolk of egg, and hence it was not clear how human rickets could be a question simply of diet and one of avitaminosis. Egg yolk was by no means a universal article in the infant dietary and of course cod-liver oil could not be considered in any sense an ordinary article of food. We now know the explanation. This is that man is able to manufacture the vitamin himself and the story of this discovery is one of the most interesting pages in the history of medicine.

It had long been observed that children and animals allowed into the open air seldom or never developed rickets, in short that rickets was a disease of urban communities, and that the transference of the rachitic child from the city slum

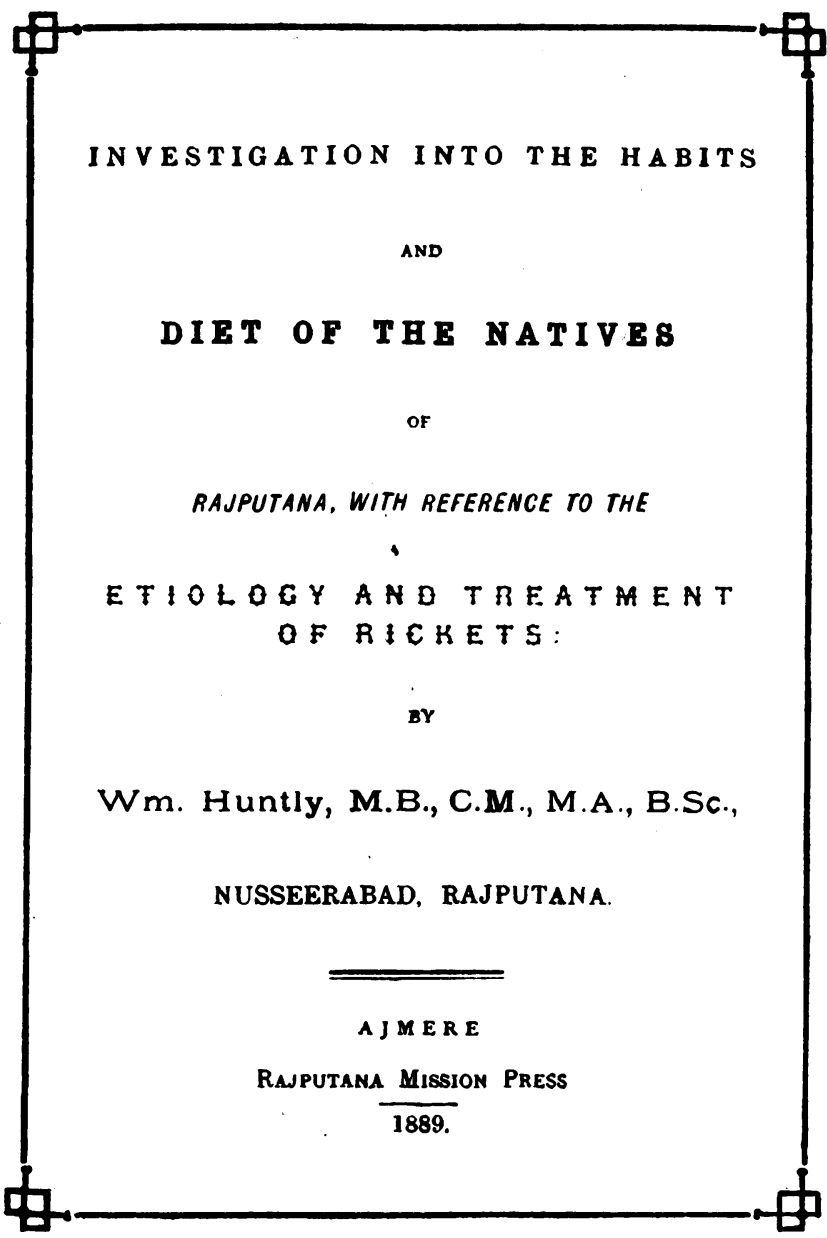

Fig. I. Reduced facsimile of title page of Huntly's pamphlet. to the country, or to the sea side, did not unusually effect a cure. Hence it became apparent that in some way an open-air life exerted a prophylactic and curative influence, but the particular element in this environmental complex remained obscure. The old thesis of Huntly, propounded in 1889 , that sunlight was a potent factor in the prevention of rickets had received little credence and the support given in 1900 by Palm to Huntly's view passed almost unnoticed. (Fig. I.) Huntly had found rickets rare, if present at all, in India; and this fact he ascribed to the abundance of sunlight since this was the paramount difference between conditions in India and in those countries in which rickets was rife. In his own words, " among external hygienic conditions the absence of open-air exercise and sunlight appear as the main factors in accentuating the tendency to its formation." Many years later Hutchison demonstrated that rickets did exist in India, but only among the wealthy Hindoo families who practised purdah, a custom which entails the confinement of the women and young children to the home. Palm, who was aware of Huntly's work, tackled the problem by making a geographical survey of the distribution of the 
disease, and from his findings it was apparent that the incidence of rickets and the amount of sunshine were inversely proportionate to one another.

The proof that Huntly and Palm had discovered an important factor in the pathology of rickets, and a factor which was to have a most far-reaching effect on our ability to combat the disease, is one, but not the only one, of the benefits which can be put against the calamities of the Great War. Until this time our only efficient treatment of rickets was the empiric administration of cod-liver oil, or a sojourn in the fresh air of the country or by the sea side. In Germany, during and after the Great War, economic conditions were so bad that cod-liver oil was hardly procurable and only the wealthiest, who of course seldom suffer from the disease, could afford to send their children to the country or to the sea side. It therefore occurred to Huldschinsky, a Berlin pædiatrician, since neither of the known cures could be applied, to test the effect of so-called artificial sunlight or the ulträ-violet rays, and in I9I9 he reported that he had been successful " by the application of artificial sunlight in four severe rachitic children to bring about almost complete healing within the space of two months." (Fig. 2.)

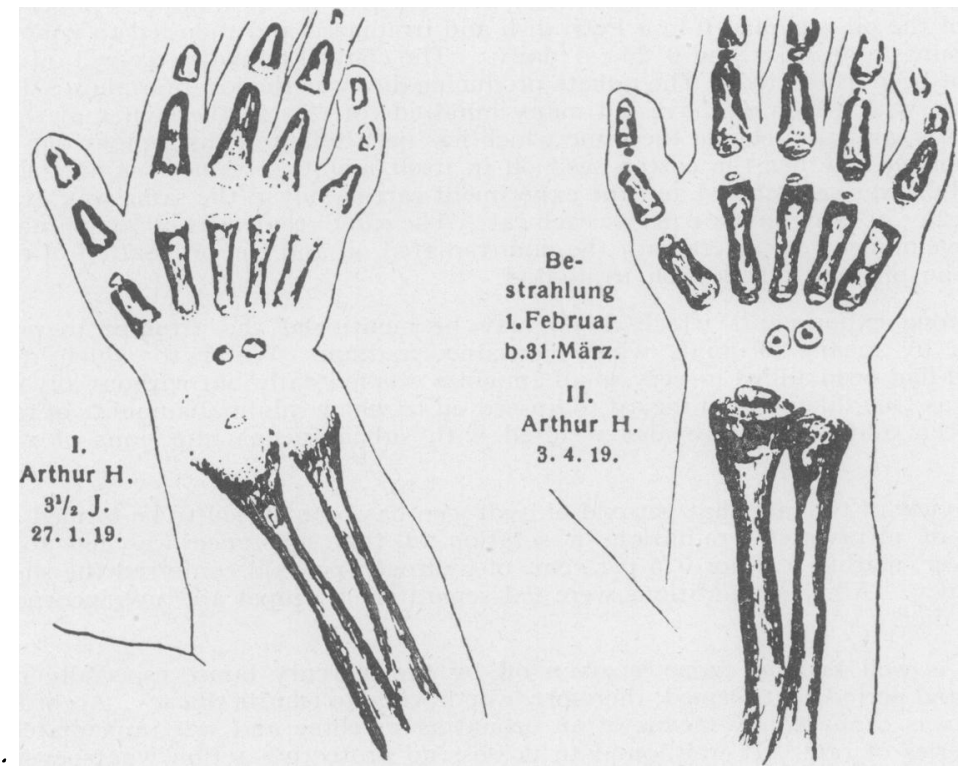

Fig. 2. Illustrations from Huldschinsky's original paper (Deutsch. med. Woch., No. 26, 1919) of X-ray photographs of the wrist showing the effect of radiation with artificial sunlight on alternate days over a period of two months.

Some few years later, when the therapeutic effect of artificial sunlight was universally admitted and practised, it occurred to A. F. Hess of New York to try the effect of the ultra-violet rays on food stuffs and see if by this means inert substances could be endowed with anti-rachitic properties. In the course of these experiments Hess found that by " exposing normally impotent cotton-seed oil to the mercury quartz vapour lamp for one hour at the distance of one foot it had acquired a definite anti-rachitic potency." Later Hess showed that rat's skin could also be rendered anti-rachitic by radiation, and he postulated that by the action of the ultra-violet rays 
some material situated in the subcutaneous tissues, and probably a constituent of fat (which he called provitamin), was transformed into the potent substance or vitamin which influences the absorption of calcium and the formation of normal bone with the prevention of the diseased condition called rickets. (Fig. 3.)

\section{EXPERIMENTS ON THE ACTION OF LIGHT IN RELATION TO RICKETS \\ Alfred F. Hess, M.D.}

Radiation has acquired a new significance for physicians within the last few years, especially for those who are concerned with the welfare and treatment of infants. Although we all realize and recognize the value of light rays in the treatment of rickets and some other diseases, it is only too true that little or nothing is known regarding the action of these rays, and the mechanism by which they produce their remarkable effect. The experiments which I wish to communicate are novel and seemed of interest in this connection.

It occurred to us to ascertain whether the treatment of inert substances with ultra light rays could endow them with antirachitic properties. With this end in view we irradiated various fluids with the mercury vapor quartz lamp. To summarize the results of these experiments it may be stated that it was found that cotton seed oil when rayed for an hour at a distance of one foot had acquired antirachitic potency. The experiments were carried out as follows: A very thin layer of the oil was placed in a Petri dish and irradiated and then fed to young rats in amounts of 0.1 c.c. and 0.25 c.c. daily. The control animals received oil which had not been irradiated. The rickets-producing diet was the low phosphoros dietary (No. 84) with which we have fed many hundreds of rats in the course of the last few years, and the technic the same which has been followed throughout our work. Questioning whether the cotton seed oil in itself might be somewhat antirachitic, linseed oil was substituted and the experiment carried out in the same way, 0.1 c.c. and 0.25 c.c. being given daily to each rat. The same result was obtained, namely, the development of rickets with the nonirradiated oil and the prevention of rickets with the oil which had been irradiated.

Among experiments which failed may be mentioned the attempt to prevent rickets by means of fluids which contained radium. Water to which radium bromid had been added in very small amounts was fed daily but without any effect. This was true, likewise, in regard to linseed oil to which minimal amounts of radium had been added. Failure also resulted with subcutaneous injections of radium water.

In view of the fact that peroxid of hydrogen has been stated to be formed as the result of ultraviolet irradiation, a solution of this substance was fed to rats. However, neither 0.2 nor 0.5 per cent. of hydrogen peroxid conferred the slightest immunity. All these additions were fed separately by pipet and not incorporated in the diet.

As is well known, ozone is given off by the mercury lamp, especially during the initial period. It seemed, therefore, worth while to test its efficacy. Accordingly, water was ozonated by means of an ozonating machine and was immediately fed to a series of rats. It was found to possess no protective action whatsoever.

Mineral oil was irradiated in the same way as the other oils, but gave a negative result when fed in the same amounts.

We shall not attempt to explain these results by means of hypotheses. It may be stated, however, that the oil was found to have been changed but little in its iodin number, that is to say, in its content of unsaturated fatty acid, although the total acidity was somewhat increased. The color was slightly bleached, as has been noted by others. Peculiarly enough it frequently acquired a somewhat fishy odor resembling that of cod liver oil. Naturally, one of the first things which suggests itself is the possible association of a phenomenon of this kind with vitamins. Whether experiments of this kind will be serviceable in furthering our knowledge regarding the formation of the antirachitic factor, or be of therapeutic value in increasing the potency of antirachitic substances, such as cod liver oil, must be ascertained by subsequent investigation. These are subjects which are occupying us at the present time.

Fig. 3. Copy of Article by A. F. Hess, from the American Journal of Diseases of Children, October, 1924, Vol. 28, p. 517. 
At first Hess and his co-workers inclined to the view that the particular sterol which could be endowed with anti-rachitic powers by the ultra-violet rays was cholesterol, known to be a constituent of every cell in the animal body. Later, however, as the result of chemical analyses and spectral absorption tests, it was concluded that it was not cholesterol but ergosterol, an allied substance, which was the provitamin stage of the anti-rachitic factor. In consequence of much intensive work which followed these discoveries, it is now known that there are probably ten varieties of sterol which can be activated to exert anti-rachitic powers in different degrees of efficiency, but there can be no doubt that two examples of provitamin D stand out pre-eminently. These are (a) 7-dehydro-cholesterol and (b) ergosterol.

(a) 7-dehydro-cholesterol, which is a constituent of the animal body, is the provitamin stage of the vitamin which the body manufactures for itself as a result of the exposure of the body surface to the sun's rays. This particular sterol is converted into the vitamin in the cutaneous tissues and from there passes into the blood stream and is distributed throughout the body. It is generally assumed that activated 7-dehydro-cholesterol is also the variety of the vitamin which is present in fish oil, e.g., cod-liver oil, but according to some workers there are biological and chemical differences which leave room for doubt on the question.

(b) Ergosterol-a sterol of the vegetable kingdom-is the provitamin stage of all artificially produced varieties of vitamin D. Ergosterol can be extracted from yeast, mushrooms and other fungi. It was first isolated in pure form by a distinguished French chemist-Tauret-from ergot, a fungus developing on grain, and hence itse name. On radiation all of the ergosterol is not rendered anti-rachitic, but only ac portion of it, and this fraction when freed from the other non-essential by-products? assumes a crystalline form and is called calciferol. Both of these forms of the vitamin retain their power when dissolved in oil and thus it is as a suspension in oil that they are employed. Activated ergosterol in oil has the trade name of viosterol.

In consequence of numerous clinical and experimental trials it has been shown conclusively that the artificially produced vitamin, i.e., from ergosterol by radiation or latterly by bombardment with low velocity electrons, is quite as efficient as that produced naturally, e.g. in eggs and fish oil. Unfortunately, however, under natural conditions the amount of the vitamin produced varies, depending as it does on the exposure to the sun's rays, the filtering effect of the surface of the body and the quantity of the provitamin 7-dehydro-cholesterol present, which are all variable factors. Hence various samples of cod oil differ in their vitamin content, as do also eggs, and for the same reason there is no constancy in the amount of the vitamin produced by radiation of the body. The same is true of the effect of the radiation of food stuffs such as milk. But in the case of the artificial vitamin the various factors in its production (amount of provitamin and time and distance of exposure to the ultra-violet rays) can be controlled and a uniformity in the product guaranteed. Moreover, with the artificial vitamin it is a practicable proposition to measure and express its potency in absolute terms, which makes it an ideal therapeutic preparation.

The potency of the vitamin preparations is measured according to the amount necessary to prevent the disease in the rat and was expressed at first in so-called "rat units," but now in consequence of an agreed and standardized technique adopted in all countries is called the "International Unit." In this way the relative strength of different preparations can be indicated. For example, .ooor milligram of 
radiated ergosterol represents I unit, i.e. 4 grams or one teaspoonful has a strength of $40,000,000$ units, whereas one teaspoonful of the most potent cod-liver oil only possesses an equivalent of 400 units or I/I00,000 of the power. When the radiated ergosterol is suspended in oil it is usually arranged that each gram of the preparation represents Io,00o units, i.e. one drop represents 222 units. It is thus seen that two drops of the artificial vitamin in oil (viosterol) have the power of one teaspoonful of the best cod-liver oil.

From this comparison the advantage of the artificial preparation is apparent. Not only is the strength of the preparation reliable but the requisite amount of the vitamin can be easily administered. However, the potency of the artificial vitamin and the ease with which it may be administered introduce one disadvantage of these preparations, viz. :- the danger of overdosage. It has been shown in the experimental animal, and in the infant as well, that overdosage causes excessive deposits of calcium not only in the growing bones but also in the tissues. In the child the first effect of overdosage is an increase in the calcium content of the blood, i.e. above 12 mgs. per cent., and an excessive excretion of calcium by the kidneys with the production of calcium casts. In the adult nausea, headache, profuse sweating and diarrhœa have been produced by excessive doses. X-ray examination of the skeleton will show excessive deposits of lime in the new-formed bone and metatastic deposits in the tissues. But with the doses recommended below none of these changes will take place. However, if the dose has been increased up to 50,000 units per day, or in the small and premature infant to only 20,000 or 30,000 units per day, the physician ought to be on his guard, and both examination of the blood and X-ray examination of the bones should be carried out.

Roughly, the child requires 2,000 times the rat dose, i.e. about nine drops of viosterol or five teaspoorffuls of cod-liver oil per day. It is generally recommended that for the prevention of rickets the administration of the vitamin should be commenced in early infancy, say at the beginning of the third or fourth week, with a dosage of 200 units (one drop of viosterol or one half teaspoonful of cod-liver oil) per day, increased after a few days to 400 units per day, after the fifth week to 800 units and after the second month to I,200 units as the daily dose. This dose of 1,200 units daily should be continued throughout the first year of life. In specially susceptible infants, e.g. the premature, it may be necessary to give larger doses, even up to I0,000 units per day. For the cure of rickets larger doses are also necessary. An average dose is I,200 units, but still larger doses are advisable and indeed are often necessary. Cases in which as many as 60,000 and even $I, 500,000$ units per day were required to bring about a cure have been described. The best indication of the dose required to bring about a cure, as well as of the proper maintenance dose, is the $\mathrm{X}$-ray picture of the wrist.

\section{The Pregnant Mother.}

It is now admitted that the susceptibility of the infant to rickets depends to a certain extent on the diet of the mother during pregnancy. Hence it is generally recommended that the pregnant woman should receive added vitamin $\mathrm{D}$ to her diet, so that optimal absorption of calcium and phosphorus can be secured. It is of course needless to point out that if these minerals are to be absorbed in sufficient amount they must be represented adequately in the diet. The optimum dose for the pregnant woman is not known but probably a dosage varying between 800 and 2,000 units per day will meet the average needs. 


\section{Dental Caries.}

It is held by a certain school that caries of the teeth is also a manifestation of avitaminosis but the evidence at present available is so conflicting that a definite $\stackrel{N}{\circ}$ opinion is not possible. Although this school believes that the absence of vitamin $\mathrm{D}$. encourages developmental defects in the dentine, they do not deny that it is the products of putrifying carbohydrates-lactic acid-which cause the actual caries. Hence the only sure means to prevent caries is by attention to mouth hygiene so that no fermentable food is allowed to lie in the crevices between the teeth. This means attention to the type of food and the regular use of the tooth brush, especially at night just before retiring to bed. In any case, in view of the almost universal practice of adding vitamin $\mathrm{D}$ to the diet of all infants and children for the prophylaxis of rickets, whether or not this vitamin helps in the prevention of dental caries is of little practical moment.

HESS, A. F., (1924), Amer. Jour. Dis. Child, xxviii, 517.

LITERATURE.

HOPKINS, F. G., (1906) Analyst, xxxi, 395.

HULDSCHINSKY, K., (1919), Deutsch. med. Wochensch., No. 26

HUNTLY, Wm., (1889), Ajmere Rajputana Press.

HUTCHISON, H. S. and PATEL, P. T., (1921), Glasg. Med. Jour., xcv, 241.

McCOllum, E. V., SIMMONDS, N., PARSONS, H. T., SHIPLEY, P. G., and PARK, E. A., (1921), Jour. Biol. Chem., xiv, 333. MELLANBY, E., (1919), Lancet, i, 407.

PALM, T. A., (1890), The Practitioner, xlv, 270. 